\title{
A LINGUAGEM E A LINGUAGEM DOCUMENTÁRIA NO PROCESSO DE REPRESENTAÇÃO DO CONHECIMENTO DE GRUPOS MARGINALIZADOS: REFLEXÕES TEÓRICAS
}

\section{LANGUAGE AND DOCUMENTARY LANGUAGE IN THE KNOWLEDGE REPRESENTATION PROCESS OF MARGINALIZED GROUPS: THEORETICAL REFLECTIONS}

Alexandre Robson Martinesa

Graziela dos Santos Lima ${ }^{b}$

Carlos Cândido Almeidac

\begin{abstract}
RESUMO
Introdução: A representação do conhecimento é responsável pela interoperatividade entre sistemas, usuários, domínios, ao mesmo tempo em que devolve à sociedade uma malha informacional legitimada e capaz de, através da recuperação da informação, oferecer viabilidade às informações articuladas. Objetivo: Assim, este trabalho objetiva analisar o impacto da linguagem no processo de representação no que tange às questões semânticas, semióticas e discursivas a fim de compreender a pré-disposição do sistema de organização do conhecimento, o qual é direcionado por escolhas terminológicas, para legitimar a representação, mais especificamente, discutir acerca da institucionalidade de conceitos e o modo como se efetua a representatividade de grupos marginalizados entendidos neste trabalho como negros/as, indígenas, ciganos/as, mulheres e pessoas do grupo LGBTIA+. Metodologia: Para tanto, aplicou-se uma metodologia de natureza qualitativa, tipo descritiva, de caráter exploratório, de abordagem teórico-bibliográfica e crítica. Conclusões: Portanto, entende-se que a representação social tem grande influência na construção da linguagem documentária e estão engendrados parâmetros hegemônicos de um determinado grupo, o que pode acarretar sub-representação de sujeitos, grupo sociais e culturais que não fazem parte do sistema simbólico de representação dominante.
\end{abstract}

a Doutorando em Ciência da Informação pelo Programa de Pós-Graduação em Ciência da Informação da Universidade Estadual Paulista (PPGCI-UNESP). E-mail: alexandre.martines@unesp.br.

b Doutoranda em Ciência da Informação pelo Programa de Pós-Graduação em Ciência da Informação da Universidade Estadual Paulista (PPGCI-UNESP). E-mail: graziela.lima@unesp.br

c Doutor em Ciência da Informação pela Universidade Estadual Paulista (UNESP). Docente do Programa de Pós-Graduação em Ciência da Informação da Universidade Estadual Paulista (PPGCI-UNESP). E-mail: carlos.c.almeida@unesp.br 
Descritores: Representação do Conhecimento; Grupos Marginalizados; Linguagem Documentária.

\section{INTRODUÇÃO}

A representação do conhecimento é um procedimento fundamental para a Organização do Conhecimento, por isso sua precisão subsidia a interoperatividade entre sistemas de recuperação da informação, a comunicação entre usuários e domínios do saber, ao mesmo tempo em que devolve à sociedade serviços de recuperação da informação. A Organização do Conhecimento é um campo de estudos interdisciplinar que propõe metodologias, análises, diretrizes e processos que trabalham com a organização do conhecimento registado (GARCÍA MARCO, 1997).

Neste trabalho, tem-se como objetivo analisar a linguagem no processo de representação, o que inclui questões relacionadas aos problemas semânticos, semióticos, discursivos e de representação social, a fim de compreender a pré-disposição da linguagem documentária1.

Particularmente, pretende-se entender o impacto da significação para a representação de grupos marginalizados entendidos neste trabalho como negros/as, indígenas, ciganos/as, mulheres e pessoas do grupo LGBTIA+2; grupos estes que estão à margem do sistema político, econômico e educacional, representados por uma cosmovisão eurocêntrica, branca, sexista, heterossexual e cristã. Portanto, é um processo pelo qual um determinado grupo social é posto em uma posição inferior na sociedade, o que é identificado como marginalização, causado pela desigualdade social (CASTEL, 2008).

É preciso refletir e questionar as categorias tradicionais inerentes à linguagem documentária, aos sistemas de organização do conhecimento e da própria área da Organização do Conhecimento como um todo, utilizadas para

1 Os pesquisadores optaram pela utilização do termo "linguagem documentária" como tema principal, pois estão utilizando uma perspectiva literária da escola brasileira da Ciência da Informação, que possui influência francesa nas quesões que versam sobre representação do documento.

2 "Lésbica, Gay, Bissexual, Transexual, Transgênero, Queer, Intersexo, Assexual, e outras possibilidades de orientação sexual e/ou diversidade de gênero." (SILVA, 2019, p. 13). 
perceber o objeto representado, os fatos e as pessoas, seja diretamente, seja através de um documento a fim de garantir que o sistema legitime a representatividade de todos os grupos sociais, assim também tendo a preocupação de evidenciar grupos marginalizados.

Nesse contexto, a linguagem documentária visa a um escopo fechado, servindo para normalizar as linguagens de especialidade que abrangem um recorte documental, ou seja, é um recorte de conteúdo de um documento que é condicionado aos procedimentos de representação, interpretação e comunicação (LARA, 1993).

Já os sistemas de organização do conhecimento (SOC) é um conceito mais amplo; a eles, incorporam-se dicionários, glossários, taxonomias e tesauros (HODGE, 2000), além de incorporar outros subsídios inerentes às inovações tecnológicas como a folksonomia no contexto digital (CARLAN, 2010). Assim, é válido destacar que os SOCs têm como base a linguagem documentária para sua configuração.

Diante disso, optou-se por eleger o termo linguagem documentária, pois o presente artigo entrelaça as formas de como o documento está representado pelo autor da obra à inquirição do profissional da informação mediante à representação do documento em torno dos grupos marginalizados.

A linguagem documentária - por mais que recorra à padronização para especificar a terminologia aplicada, buscando estabilizar o significado tratado no documento para que se efetue a representação - quando não considera os fundamentos referentes à enunciação, ao discurso e à significação inerentes a qualquer tipo de linguagem, permite que particularidades do conhecimento humano não sejam evidenciadas.

Nessa linha, evidencia-se que a escolha terminológica reproduz ideologias, intencionalidades, atos comunicacionais e marcas discursivas de um segmento científico, assim como os fatores históricos que constituem a evolução do desenvolvimento de um conhecimento e sua legitimação por um determinado grupo.

Diante do que foi mencionado, este estudo produz uma reflexão sobre a aplicação das teorias linguístico-semióticas e da teoria das representações 
sociais quando se trata de representar o conhecimento de grupos historicamente marginalizados pela linguagem documentária. Assim, o presente trabalho segue uma abordagem teórico-bibliográfica, pautado em teorias linguísticas, semióticas e das representações sociais. Além disso, esse arcabouço teórico auxilia a análise do trabalho terminológico para a representação do conhecimento; bem como ajuda a avaliar o impacto das escolhas presentes na linguagem documentária no processo de representação dos grupos marginalizados.

Entende-se que a função primordial da linguagem é a comunicação, somado ao fator de representar e mediar a realidade através da significação, fato este capaz de promover perspetivas sobre a definição de um determinado objeto, atribuindo-Ihe concepções culturais, psíquicas, sentimentais.

Em relação à representação do conhecimento, a Organização do Conhecimento visa a um significado unívoco capaz de estabelecer um pensamento, por conseguinte apto a estabelecer diretrizes para nortear a modelação de conceitos, os quais atuam como propulsores de novo conhecimento.

Sendo assim, aplica-se a linguagem documentária para evidenciar o arcabouço científico e legitimar a linguagem científica, pois a interação entre integrantes da mesma cultura, da mesma comunidade discursiva, caracterizando a mesma esfera intelectual é responsável pela produção de novas perspectivas e pela ressignificação dos saberes.

Diante disso, esta pesquisa baseia-se em teorias da linguagem (SAUSSURE, 2006; GREIMAS, 1973; PEIRCE, 2017; BENVENISTE, 1988; MAINGUENEAU, 1996; BAKHTIN, 2006; FOUCAULT, 2006; PÊCHEUX, 2015) e na teoria das representações sociais (MOSCOVICI, 1978, 2003; ALVESMAZZOTI, 2000; GUARESCHI; JOVCHELOVITCH, 1995) a fim de evidenciar diversas situações geradoras de significação para compreender o impacto das escolhas da linguagem documentária, consequentemente a eleição específica de seus termos para representar o conhecimento presente em documentos, ou evidenciar a terminologia de um determinado domínio ou comunidade discursiva. 
Torna-se importante debater sobre a força discursiva presente nessas escolhas e a marca de fatores ideológicos que acabam definindo processos de representatividade social de grupos historicamente excluídos.

\section{LINGUAGEM E REPRESENTAÇÃO DO CONHECIMENTO}

A linguagem é o instrumento humano responsável pela mediação entre a realidade, o pensamento, a cognição e a comunicação, ou seja, é um aparato simbólico, carregado de valores sociais, históricos e ideológicos utilizados para representar os objetos, os fenômenos e as práticas que perfazem a vida humana.

Diante desse propósito, o signo é elemento simbólico responsável pela relação entre 0 objeto a que representa e 0 aparato de linguagem que 0 designa, assim tem-se o significante (imagem acústica) somado ao significado (conceito) para formar um signo, de valor arbitrário, pois é estabelecido pela força da coletividade (SAUSSURE, 2006, p. 81).

Vale destacar que a Semântica Estrutural (GREIMAS, 1973; SAUSSURE, 2006) e a Análise do Discurso (MAINGUENEAU, 1996; BAKHTIN, 2006; FOUCAULT, 2006; PÊCHEUX, 2015) também se apoiam na definição diádica do signo (significante e significado), porém debatem sobre a questão da significação, pois o signo não é propriamente entendido como arbitrário e imotivado, mas sim como reflexo de uma convenção social. No entanto é possível haver transformações na substância do significado, através de descrições metalinguísticas ou fenômenos semióticos.

Já para a Semiótica peirceana, o signo é triádico, constituído por um representamen, um objeto e um interpretante. Da conexão entre eles, emana uma semiose. A semiose traduz própria natureza do signo, a continuidade, ou seja, "um signo, ou representamen, é aquilo que, sob certo aspecto ou modo, representa algo para alguém" (PEIRCE, 2017, p. 46).

É neste ponto em que a tríade do signo oferece uma concepção sobre a realidade de modo diferenciado em relação à Linguística, já que aponta à vital interferência do extralinguístico e do inerpretante. Assim, a definição ressalta 
que o signo "dirige-se a alguém, isto é, cria na mente dessa pessoa, um signo equivalente, ou talvez um signo mais desenvolvido" (PEIRCE, 2017, p. 46), fator consequente da semiose responsável pela significação, assim como pela construção e ampliação do conhecimento.

Dessa maneira, destacam-se os fundamentos teóricos acerca do signo: o entendimento de Saussure (2006) sobre a linguagem é norteador da configuração da linguagem documentária nas escolas francesa, inglesa e brasileira. Segundo o autor, a linguagem é constituída de uma dicotomia estabelecida em langue (língua) e parole (ato de fala). Destacando o uso da primeira, a langue é entendida como um sistema social. Nesta linha, a língua "não se confunde com a linguagem; é somente uma parte determinada, essencial dela" (SAUSSURE, 2006, p. 21).

Assim, a concepção de Saussure (2006) é baseada nas teorias idealista e monista, que entendem o conceito como absoluto e anterior à experiência, como aponta S. Agostinho, por volta do ano de 400, além de também dialogar com as teorias nominalista e mentalista, que defendem que o conceito é reproduzido pela própria palavra e não há relação de representação do objeto (REALI; ANTISERI, 2014), defendido por por G. W. Leibniz, em 1686, à base de fundamentos da escolástica e do raciocínio mecanicista que propõe o novo significado das formas substanciais (REALI; ANTISERI, 2014, p. 41).

Essa concepção corrobora a defesa de que a língua é imotivada, ou seja, é resultado tão somente de uma arbitrariedade e convencionalidade. Esses fatores motivaram o entendimento de que a linguagem documentária é a própria metalinguagem, como definido pelas escolas francesa, inglesa e brasileira, compreendendo, assim como resultado. Porém, as teorias da linguagem que estudam a substância da palavra, ou seja, o processo de significação, defendem que metalinguagem é um processo descritivo, não o resultado, pois se caracteriza por ser a descrição de uma concepção sob novas concepções, a sistematização de um significado através da performance de uma outra significação. (BENVENISTE, 1988; HJELMSLEV, 2013).

Em outra perspectiva acerca da representação da realidade, pode-se alinhar à semiótica, principalmente a de Charles S. Peirce (1839-1914), no 
intento de considerar que os elementos da linguagem se perfazem pela constituição de um signo. Nesse sentido, representação ou signo "é tudo aquilo que está relacionado com uma segunda coisa, seu Objeto, com respeito a uma Qualidade, de modo tal a trazer uma terceira coisa, seu Interpretante" (PEIRCE, 2018, p. 28).

Primeiramente é preciso destacar as categorias fenomenológicas na teoria peirceana. As categorias fenomenológicas são classificadas em três instâncias: primeiridade, secundidade e terceiridade. Diante de tal fato, tem-se que "ser tal como aquele ser é, independentemente de qualquer outra coisa" ausência de qualquer referência ou esforço, denominou-se Primeiridade; a binariedade, o confronto, a obsistência - "aquele elemento que, tomado em conexão com a Originalidade, faz de uma coisa aquilo que uma outra a obriga a ser" - denominou-se Secundidade; por fim, a experiência, a mediação que efetiva o hábito, o estar apto para agir, a ação da mente (significação), a transuação - mediação, ou modificação - chama-se de Terceiridade (PEIRCE, 2017, p. 27).

A consciência é recorrente às sensações, ao confronto e à mediação da mente com o objeto, por isso Peirce estabeleceu as categorias fenomenológicas. Nessa perspectiva, "a palavra signo será usada para denotar um objeto perceptível, ou apenas imaginável, ou mesmo inimaginável num certo sentido" (PEIRCE, 2017, p. 46). Além disso, "para que algo possa ser um signo, esse algo deve representar, como costumamos dizer, alguma outra coisa, chamada de objeto" (PEIRCE, 2017, p. 47).

Somado a isso, há a configuração do signo e sua composição que é sempre triádica, pois dialoga diretamente com as categorias fenomenológicas. O signo, por sua vez, é formado por um diagrama inicial: representamen, objeto e interpretante, sob os quais se formam novos diagramas, também triádicos para evidenciar as suas relações também com as categorias fenomenológicas. Assim, sob o representamen há a configuração de uma tríade: qualissigno, sinsigno e legissigno; para o objeto: ícone, índice e símbolo; para o interpretante: rema, dicente ou dicissigno e argumento.

As tricotomias relacionadas ao representamen são o qualissigno, o 
sinsigno e o legissigno (SILVEIRA, 2007; IBRI, 2015; PEIRCE, 2017), assim entende-se como qualissigno "signo devido à sua potência de significar"; o sinsigno "significará na justa medida em que existir", em outras palavras "o existente consiste em uma configuração de qualidades em conflitos e será através dessas qualidades conflitantes que 0 existente enquanto tal constituirse-á num signo, no caso, um sinsigno" (SILVEIRA, 2007, p. 68).

Por fim, o terceiro membro denominado de legissigno que, conforme aponta Peirce, é "uma lei que é um signo", o que caracteriza por ser um tipo geral e não restrito a um objeto singular, mas a ele há "concordância a respeito", assim "todo legissigno ganha significado por meio de um caso de sua aplicação", esse fator é denominado de réplica (SILVEIRA, 2007, p. 68).

Por sua vez, o objeto atua como signo sob duas maneiras, que estabelecem relação com 0 interpretante, formalizando a relação da familiaridade entre o signo e o objeto que o representa, isto é, o objeto pode ser denominado de imediato, quando não há evidência de familiaridade entre o objeto e o signo, caracterizando como uma referência geral, sem particularidades ou detalhes, apenas como se representa. Dessa maneira, a relação com o extralinguístico é mínima, apenas sendo atribuído um significado restrito (SILVEIRA, 2007; PEIRCE, 2017).

Já o objeto dinâmico, caracteriza-se por promover uma maior incidência de familiaridade, de experimentação e experienciação, portanto havendo uma maior relação com a experiência colateral. Através dessa relação, a constituição do objeto é maior e mais complexa. Como objeto imediato, as representações históricas sobre os grupos marginalizados podem ser genéricas, sem muitos detalhes ou aprofundamentos. Já na relação com o objeto dinâmico, resultado de interação com a experiência colateral, essa representação é abrangente, evidenciando mais informações e eventos como comportamento, hábitos culturais, práticas sociais, relações políticas no processo de existência e reconhecimento.

Assim, o objeto dinâmico se configura como um conjunto, ou uma totalidade de partes, ao qual recai circunstâncias da experiência, por conseguinte a resistência de aspectos mais complexos da significação, 
realmente eficiente. "É sobre o objeto dinâmico que recai a tríade de diagramas do objeto" (SILVEIRA, 2007, p. 73).

Relacionados ao objeto dinâmico, estabelecem-se as tricotomias do objeto, "um ícone é um signo que se refere ao objeto que denota apenas em virtude de seus caracteres próprios [...] qualquer que seja uma qualidade, um existente individual ou uma lei", sendo assim o ícone ainda não é suficiente para a significação devido ao fato de se restringir apenas à semelhança, porém é essencial, devido ao aspecto primeiro, ou seja, a evidência de traços de qualidades que fundamentam o objeto: "é ícone de qualquer coisa, na medida em que for semelhante a essa coisa e utilizado como um seu signo" (PEIRCE, 2017, p. 52).

Já o "índice se caracteriza por ser um signo que se refere ao objeto que denota em virtude de ser realmente afetado por esse objeto" (PEIRCE, 2017, p. 52). Nessa linha, o índice ainda não evidencia o objeto em sua constituição plena, mas sim uma relação de continuidade e existência com a sua referência, a qual possibilita a interação do objeto com seu destinatário.

Por fim, "um símbolo é um signo que se refere ao objeto que denota em virtude de uma lei, normalmente uma associação de ideias gerais que opera no sentido de fazer com que o símbolo seja interpretado como se referindo àquele objeto" (PEIRCE, 2017, p. 53). Dessa forma, entende-se como uma lei, portanto atrelado diretamente ao um legissigno.

Assim, aquilo que o legissigno é para o representamen; o símbolo é para o objeto, dessa forma contribuindo para a construção de seu significado como fundamentados por uma convencionalidade, porém o símbolo é parcialmente convencional, isto é, ele carrega a convencionalidade, pois há uma generalização à força do hábito, do objeto imediato, todavia há margens para a significação, devido à ampliação da experiência proporcionado pelo objeto dinâmico, ou seja, quanto maior for o impacto da experiência colateral na perspectiva de ampliar as definições desse objeto, melhor realizado e definido será esse símbolo.

Por sua vez, o interpretante se efetiva por ser parte fundamental do signo a fim de se estabelecer a semiose. Assim, pode-se destacar que o 
interpretante "constitui-se, pois, no terceiro correlato da tríade semiótica" (SILVEIRA, 2007, p. 45). Sobre este correlato é importante também destacar que sua função é o resultado, a significação, ou seja, "o representamen fará com que, por seu intermédio, seja produzida uma ideia do objeto" (SILVEIRA, 2007, p. 45). Diante disso, entende-se que o conceito, na visão semiótica, realiza-se no terceiro correlato da tricotomia do signo.

Para Peirce, um rema "é um signo que, para seu interpretante, é um signo de possiblidade qualitativa, ou seja, é entendido como representando esta ou aquela espécie de objeto possível" (PEIRCE, 2017, p. 53). Portanto, esse tipo de signo não é suficiente para estabelecer, efetivamente, significado ou significação, mas aponta possibilidades.

Já o dicissigno ou dicente, Peirce define que "é um signo que, para o seu interpretante, é um signo de existência real" (PEIRCE, 2017, p. 53). Ademais, Silveira (2007, p. 82): "todo signo que será caracterizado como dicissigno será passível de julgamento que considere verdadeiro ou falso quanto à representação do objeto, o que não era o caso do Rema, que era tãosomente um interpretante de possibilidade".

Por fim, Peirce define que um argumento "é um signo que, para seu interpretante, é signo de lei" (PEIRCE, 2017, p. 53), fator que por sua própria natureza evoca o significado, já que o argumento ser um signo de lei: "apresenta-se a classe mais geral dos signos, aquela que, no interior da terceira tricotomia, constitui-se a terceira classe" (SILVEIRA, 2007, p. 87), assim caracteriza-se como plenitude total.

Nessa linha, pode-se entender que um termo, utilizado para representar um conceito, pode ser visto como legissigno (um tipo de signo de lei ou convenção na esfera do representamen) na teoria semiótica peirceana; e o conceito pode ser reconhecido como elemento constituído pelas características inerentes à tricotomia do objeto e à tricotomia do interpretante (efeito de significado), embora sejam suscetíveis à semiose ilimitada (processo contínuo e ininterrupto de significação), que deve ser compreendida como "qualquer coisa que conduz alguma outra coisa (seu interpretante) a referir-se a um objeto ao qual ela mesma se refere (seu objeto), de modo idêntico, 
transformando-se o interpretante, por sua vez, em signo, e assim ad infinitum" (PEIRCE, 2018, p. 74).

Porém, no processo de representação, o valor de um conceito pode ser estabilizado pela experiência, fator que inibe a ressignificação desses conceitos devido a sua tradição, assim podendo interferir no entendimento de determinados conhecimentos vistos por outros interpretantes, ou seja, termos tidos como procedimento comum podem não garantir a legítima representatividade dos grupos excluídos, ou por não evidenciar seus traços culturais, ou por evidenciarem estereótipos ou difamação.

Defende-se com base na semiótica que conceito de um termo é um estágio do signo, pois os conceitos mudam e se atualizam mais rápido que os termos. Nesse sentido, é preciso compreender que há escolhas ideológicas que interferem no processo, portanto o suposto consenso pode interferir na escolha de termos mais precisos, mesmo que manuais e o apontamento ético indiquem ser o mais adequado, todavia pode ser reflexo de um hábito consolidado, e não a forma de representação adequada diante das necessidades sociais.

É preciso entender que alguns estágios do signo são responsáveis pela estereotipação ${ }^{3}$, pois refletem o estágio mental inerente ao interpretante, sendo assim os objetos podem ser representados apenas por sua concepção imediata, não havendo a inquirição sobre suas significações dinâmicas, desse modo não recuperando a informatividade discursiva, isto é, o conjunto de proposições e pressupostos inerentes à precisão de determinados conceitos articulados em determinados contextos, que envolvem os diferentes pontos de vista produzidos pelos diferentes grupos sociais e discursivos alinhados a um determinado conhecimento.

Nessa produção, apenas a presença de um discurso marcado pelos objetivos e pela natureza do domínio pode determinar um processo de organização do conhecimento tendencioso a apenas evidenciar o que é

\footnotetext{
${ }^{3}$ A estereotipação acontece por meio da semiose ilimitada, que vem do ato de reinterpretação contínua dos signos, que origina outros signos-interpretantes, que por via de hábitos nas práticas humanas reproduzem-se e seguem certos padrões, que pode ser negativo ou positivo.
} 
institucionalizado pelos grupos, domínios e comunidades discursivas que possuem mais poder.

O viés histórico, por exemplo, pode ser prejudicado, visto que os documentos da época narram os fatos históricos pela perspectiva do colonizador, e a aplicação da linguagem documentária, que não é marcada por circunstâncias discursivas de interesses ideológicos de outros domínios ou de outras instituições cujo poder seja determinante para também legitimar a representatividade, afasta determinados grupos, normalmente excluídos, e sua representatividade da Organização do Conhecimento.

Além disso, a linguagem documentária utilizada para elaborar um documento secundário pode assumir o valor indicial em relação ao objeto, ou seja, o termo aplicado na representação do conhecimento pode induzir a uma percepção parcial sobre o documento, já que não representa a sua totalidade: "Um Índice é um signo que se refere ao Objeto que denota em virtude de ser realmente afetado por esse Objeto" (PEIRCE, 2017, p. 52), ou seja, a linguagem documentária é afetada pelo documento primário, assim como é afetada pelo discurso dominante do domínio e da comunidade discursiva, todavia o termo, não é o documento, mas uma alusão a ele.

O extralinguístico compreende fatores que não estão presentes no linguístico e no enunciado, contudo são responsáveis pela significação produzida, isto é, na enunciação, que se caracteriza por se constituir naquilo que não foi dito, mas foi significado. Para entender o fenômeno extralinguístico deve-se apontar para a experiência colateral, conceito semiótico importante que concebe a aproximação direta entre intérprete e objeto dinâmico.

Nessa linha, entende-se que tal "experiência supõe confronto com o outro, permitindo uma representação desse confronto" (SILVEIRA, 2007, p. 27). É a experiência que promove a compreensão dos discursos e dos domínios, ou seja, "a representação será sempre um processo mediador entre o sujeito que conhece o objeto conhecido e será sempre um acréscimo de perfeição no sujeito" (SILVEIRA, 2007, p. 27).

$\mathrm{Na}$ prática da representação do conhecimento, muitos termos são evidenciados não através de reflexão, ou aplicação da lógica, do raciocínio, ou 
ainda contemplado pela inquirição de sua significação, mas sim por uma prática estabelecida por uma rotina.

Os termos, compreendidos como signos, assumem a terceiridade no representamen, já que é para um representamen um legissigno, pois o termo já é uma lei (PEIRCE, 2017, p. 53), fator que evidencia que a representação é uma prática potencializada e atualizada pela rotina estabelecida pela ideologia de um domínio, por conseguinte termos destinados a representar grupos marginalizados nem sempre ganham destaque na elaboração do documento secundário.

Diante disso, pode-se entender que a representação do conhecimento, a partir de uma terminologia consagrada pela tradição, está enquadrada em um diagrama, um esquema, o que efetua a atuação de uma determinada prática, através de dispositivos pré-concebidos. Devido a isso, pensar em representar o conhecimento pelo viés dos grupos excluídos é promover, a priori, um esforço duplo que visa à compreensão do que se é efetuado tradicionalmente e a proposta de inovação à base da inquirição.

Para o objeto a que se refere, o termo é um símbolo, já que a produção do texto secundário visualiza uma representação estabilizada do conteúdo do texto, algo que pode ser associado ao signo saussuriano, portanto definido em significante e significado, estando no significante toda a potencialidade que evoca o conceito.

Na perspectiva de Peirce, é denominado como um símbolo, pois a ele estão associadas ideias gerais, já que a experiência, que atua como força bruta, exigindo esforço de um sentido estabilizou sua aplicação para a representação de determinados conceitos: a prática é confirmada à base de réplicas de dispositivos sociais já internalizadas pelo trabalho de representação do conhecimento, os quais não questionam as proposições do dicente, ou seja, não questionam a atualização das proposições diante das dinâmicas sociais, pois, muitas vezes, estas se estabelecem através das orientações de normas e manuais.

Além das abordagens linguístico-semióticas sobre a língua - de um lado, a convencionalidade do signo da teoria saussureana, e de outro, o confronto 
com a realidade da teoria peirceana -, é nos produtos da Terminologia, área científica fundamental para contribuir com a linguagem documentária no âmbito da Organização do Conhecimento, em que a representação do conhecimento produzida pelos grupos marginalizados se evidencia como insatisfatória.

A Terminologia tem proposto caminhos para contribuir com a linguagem documentária. Pode-se definir a Terminologia em dois grandes eixos de trabalhos ao longo da história. Como aponta Lara (2006, p. 3) "o ponto de partida de Wüster era a lógica clássica visando à criação de uma teoria e de uma metodologia da terminologia como contribuição à comunicação sem ambiguidade".

Diante disso, reconhece-se a relação intrínseca com a Lógica para compreender os aspectos semânticos aplicados, assim a Teoria Geral da Terminologia "trata os conceitos como anteriores à sua expressão na linguagem", portanto busca-se a "objetividade, a precisão e a nãoambiguidade" (LARA, 2006, p. 3). A Terminologia é constituída sob normas responsáveis pela modelagem de conceitos e apresenta traços estruturais, que se aproximam ao entendimento de língua condicionada pela Linguística saussureana.

Assim, a Terminologia clássica defendia a busca pela univocidade, ou seja, a capacidade de ter apenas uma denominação, uma acepção, independente do contexto, era uma diretriz.

Por outro lado, a Teoria Comunicativa da Terminologia procura aproximar a representação do documento com a linguagem aplicada pelos domínios e comunidades discursivas, visto que a sua atuação é direcionada por três diretrizes: social, cognitiva e linguística.

Outrossim, a teoria busca centralizar o trabalho de representação nas especificidades da área-objeto, além de estreitar a aplicação terminológica com sua contraparte da linguagem natural e ser o caminho para alcançar uma representação adequada dos grupos marginalizados, todavia ainda não é suficiente para garantir efetivamente a representatividade de grupos marginalizados.

Esse embate ainda ocorre embora a escolha de termos seja 
estabelecida sob critérios temáticos e pragmáticos, procedimentos que deveriam favorecer a representatividade, porém a estratégia ainda está muito presente na abordagem generalizada estabelecida pelas práticas de representação, as quais apenas sofrerão alterações de escolhas terminológicas caso haja intervenções de interesses e, mesmo assim, a linguagem documentária aplicada é limitada, pois, os tesauros, os códigos da Classificação Decimal de Dewey (CDD) e da Classificação Decimal Universal (CDU), na maioria das vezes, não preveem esse tipo de representação.

Dessa forma, entende-se que há uma prática discursiva na elaboração dos documentos, assim também há um discurso dominante responsável pela confecção do documento secundário, responsável pela representação do primeiro. Em outras palavras, a própria organização do conhecimento supõe um discurso dominante, o qual se efetua pela intencionalidade, historicidade e ideologia dos domínios e das comunidades discursivas, mesmo que sejam aplicadas para garantir a coerência interna da organização do conhecimento.

É diante disso que se deve considerar que sempre haverá aspectos positivos e negativos na construção da discursividade, portanto é necessária a inquirição para debater continuadamente sobre os impactos das linguagens documentárias e a evidência semântica que estão sendo propostas.

Outrossim, historicamente, não há muitos documentos, produzidos por grupos que não pertenciam à elite discursiva ou que socialmente não sejam legitimados, dessa forma, veiculados pela prática da institucionalidade (FROHMAN, 2008).

Muitos dos documentos produzidos, no período colonial, eram relatos de viajantes, cientistas e juristas, com o propósito de justificar invasões territoriais e a escravidão. Em tempos atuais, em reflexo do que se pode observar no decorrer da construção histórica, os documentos/bibliografias produzidas por grupos hegemônicos, auferem status e importância (científica, social e cultural) em detrimento dos documentos/ bibliografias produzidos por grupos não hegemônicos, que não auferem o mesmo valor.

Há nos discursos a marca de uma disputa ideológica entre os grupos, que possuem discurso institucionalizado e os grupos que se caracterizam por 
movimento de afirmação. Não se deve restringir esse conceito ao entendimento de uma disputa econômica, pois a disputa de classes, gênero e raça evidencia uma disputa discursiva, em que as intencionalidades presentes na confecção dos documentos são empoderadas pelas necessidades, mas, principalmente, pelos interesses sociais e políticos, em destaque para quem veicula as informações.

Diante disso, entende-se ser importante explorar aspectos linguísticos e semióticos presentes no discurso para as discussões acerca do processo de representação de grupos marginalizados na Organização do Conhecimento.

Sobre a Linguística Estrutural, destacam os estudos de A. J. Greimas (1973) acerca dos fenômenos semânticos, para tanto o autor indica o lexema como produto do léxico, elemento de articulação do discurso e marcado pela incidência de unidades mínimas de significação: os semas.

Os semas são interdependentes e responsáveis pela correlação semântica entre os traços que fundamentam a aplicação do léxico em um contexto e sua relação com outros léxicos, de natureza próxima (sinonímia), ou distante, já que a base semântica é constituída por binômios que configuram seus limites de significado.

Diante do exposto, tem-se por exemplo a palavra "mulato"4 (no sentido linguístico e cultural), a qual carrega semas que constituem a presença do ser humano, masculino ou feminino, referente a cor da pele miscigenada, estereotipação associada à etnia/raça. Porém, um de seus semas carrega traços pejorativos referente à comparação dos sujeitos escravizados (no período colonial) a mulas (animal de carga). Sendo assim, o lexema durante um tempo foi aplicado para indicar a cor da pele, no entanto não se pode desassociar da função como semema, que carrega todas as marcas históricas de significação.

\footnotetext{
4 "1) linguístico - derivação de 'mulus', do latim, atualizado por 'mula', o animal que surge da cópula de duas raças diferentes - 0 asno e a égua, que, no século $\mathrm{XVI}$, derivou-se na América hispânica para 'mulato' como uma analogia ao caráter híbrido do animal, considerado uma raça inferior, já que não possui a possibilidade da reprodução; e 2) cultural - a falsa impressão de democracia racial que há no país, associado à representação da mulher negra ou mestiça através do corpo branqueado e hiperssexualizado". (SILVA, 2018, p. 77)
} 
Essas marcas são denominadas de classema: conjunto de significados que formam outros signos, sendo estabilizados a partir da relação de uma cadeia de semas, ou seja, os termos pejorativos são carregados de marcas simbólicas e históricas que deslegitimam a representatividade do grupo perante alguns domínios ou comunidades discursivas. Assim, há a relação entre o termo negro e sexualidade, perversão, malandro, violento, marginal, crioulo doido e favelado (CANDIDO; FERES JÚNIOR, 2019). Sobre essa relação semântica, ocorre um fenômeno linguístico denominado de isotopia: "interatividade no decorrer de uma cadeia sintagmática, de classemas que garantem ao discurso-enunciado a homogeneidade" (GREIMAS; COURTÉS, 2016, p. 276).

Sobre as marcas discursivas, é válido destacar os estudos acerca da semiótica do discurso presente na Análise do Discurso. Nessa perspectiva, é válido destacar o trabalho de Pêcheux no que tange a relação entre discurso e ideologia: "processos materiais se tornam signos no processo social da semiose, têm-nos servido de base à análise de categorias semânticas signo e significação" (PÊCHEUX, 2014, p. 16-17).

Ainda sobre a incidência da linguagem aplicada ao discurso na construção da simbologia social, vale destacar que a linguagem é "um sistema de signos verbais que serve para formular pensamentos no processo de reflexão da realidade objetiva pela cognição subjetiva e para comunicar socialmente esses pensamentos sobre a realidade" (PÊCHEUX, 2014, p. 17).

Ainda sobre a Análise do Discurso, destaca-se 0 trabalho de Maingueneau (1996), em que o autor destaca a enunciação no papel que assume o autor ao elaborar seu texto ou documento, ou seja, o papel do discurso ao registrar léxicos e construir sentenças, as quais em seu teor sintagmático são responsáveis pelas predicações, por conseguinte pela sistematização semiótica de descrições metalinguísticas acerca do conteúdo e, assim, definir os conceitos conforme uma perspectiva subjetiva, a qual, ao ser materializada, ganha dimensões de objetivação que norteiam o imaginário social.

Tal fenômeno linguístico pode ser visto, por exemplo, definindo termos 
pejorativos para retratar os grupos marginalizados, ou a rejeição de termos e informações que garantam a representatividade desses grupos. Assim, não deve conceber a língua "somente como léxico associado a regras fonéticas e morfossintáticas, mas também sistema que permite aos locutores que se apropriem dela de alguma maneira a fim de produzir seus enunciados particulares" (MAINGUENEAU, 1996, p. 7).

Ainda sobre a construção do discurso à base de fatores subjetivos alinhados à enunciação, o autor ainda destaca o papel da dêixis: recurso de economia discursiva em que se resgata parcial ou totalmente um enunciado, os quais são responsáveis por dinamizar a comunicação.

Dessa forma, os termos atuam como dêixis na representação de um documento frente a um domínio, porém é preciso questionar se essa aplicação resgata todos os fatores isotópicos, pois é preciso reconhecer que a atuação da linguagem documentária não é limitada ao processo gerador de significação em nível lexical, mas há uma interação descritiva, semântica e discursiva na produção da significação, além do papel indicial para a cognição.

Ainda sobre o impacto do discurso e suas marcas ideológicas, é necessário debater as ideias de Bakhtin. Segundo o autor, "tudo que é ideológico possui um significado e remete a algo situado fora de si mesmo. Em outros termos, tudo que é ideológico é um signo. Sem signos não existe ideologia" (BAKHTIN, 2006, p. 31).

A comunidade discursiva aplica suas diretrizes e ambições ideológicas, o orquestramento de uma terminologia específica é ideológico. A ideologia é um recorte de uma determinada atuação social, não é neutra, porque "todo instrumento de produção pode [...] se revestir de um sentido ideológico" (BAKHTIN, 2006, p. 32).

Desse modo, entende-se que a representação, por mais que siga a princípios éticos e haja uma norma para amparar sua atuação, é um procedimento marcado por concepções ideológicas constituídas ao longo dos anos, e o conjunto de signos que evidenciam a rede semântica demonstra, através de marcas discursivas, essa presença ideológica, podendo ser marcas positivas ou negativas, de tensividade forte, fraca ou relativa. 
Deve-se enfrentar esse problema levantando a bandeira do direito à autorepresentação, similar ao conceito de autodeterminação empregado para as nações. A autodeterminação sustenta o direito que uma nação tem de se autorregular, autogerir e ter autonomia frente a outras nações.

Em outras palavras, seria o direito que um grupo dominado ou marginalizado tem de se autorrepresentar, assegurados sempre os procedimentos metodológicos e científicos para a averiguação da convencionalidade na produção dos termos e na fixação dos conceitos. Os termos devem surgir dos grupos e eleitos por seus integrantes de modo a refletir verdadeiramente como se identificam e como se representam e querem ser representados.

A representação deve visar à opinião de um grupo para melhor garantir o acesso à informação, a opinião do grupo de usuários está fundamentada em uma cosmovisão, portanto é ideológica por natureza. Nessa perspectiva, é necessário estipular princípios objetivos para estabelecer as premissas da fundamentação do conhecimento. Por mais que a natureza das acepções represente aspectos ideológicos de seus produtores/autores, a ciência deve aplicar métodos a fim de garantir a correção dos argumentos ao longo do tempo. Essa correção reconhece o processo de semiose, lançado por Peirce, como fundamental.

Entende-se que a representação do conhecimento, por muitas vezes, carrega traços da definição saussureana acerca do imotivado em sua prática, já que se espera que os termos escolhidos sejam capazes de representar os conceitos em sua totalidade, como uma acepção absoluta, porém é preciso reconhecer que se produz constantemente a semiose na sociedade.

Neste cenário de representatividade dos grupos marginalizados, é necessário compreender os aspectos semânticos produzidos por grupos discursivos que acabam efetuando sua significação social, cultural, política, visto que os conceitos são signos, sendo estes ideológicos, por conseguinte os termos que serão escolhidos para evocá-los tendem a identificar o discurso da comunidade discursiva, ou melhor, do discurso de quem detém o poder. 
Os grupos que tiveram seus discursos abafados ao longo da história ${ }^{5}$ hoje são tratados como minorias, termo que carrega ideologicamente 0 conceito de fragilidade, inibindo o movimento de protagonismo discursivo e tem sua representatividade ainda em um patamar cinzento e questionável.

Destarte, é lícito questionar o papel da linguagem documentária e a ideologia por trás de sua estruturação nesse processo de legitimação e representatividade dos grupos sociais que há muito foram excluídos não só das práticas realistas e da própria materialidade simbólica, mas, efetivamente, dos discursos sociais. A representação do conhecimento segue procedimentos éticos, mas também segue diretrizes políticas.

\section{REPRESENTAÇÃO SOCIAL E GRUPOS MARGINALIZADOS}

As representações sociais se configuram como uma teoria que viabiliza as representações de indivíduos e/ou grupo, objetos e acontecimentos, em determinado contexto, sociedade e cultura. São representações advinda de conhecimento coletivo, suscetível aos diversos fatores como ideologias, tais como preconceito, racismo, sexismo, patriarcalismo, homofobias, dentre outros que, construídos no senso comum, naturalizam-se, criando o imaginário social, que se estrutura coletivamente de maneira simbólica enquadrando um determinado grupo em sub-representação.

A premissa é que as representações sociais de um grupo marginalizado, representado pela própria sociedade, contribuíram no processo de elaboração da linguagem e, por sua vez, da composição de linguagem documentária, tornando esses indivíduos representados de uma maneira limitada podendo ser negativa, invisibilizada ou sendo sub-representados/as.

Nesse sentido, a presente seção versa sobre as representações sociais de grupos historicamente marginalizados, que, no processo de colonização, foram retratados de maneira negativa/pejorativa, sendo essa imagem disseminada por diferentes canais de comunicação até os dias atuais, modelando saberes socialmente construídos e partilhados na sociedade e, por

\footnotetext{
${ }^{5}$ População de origem africana, povos indigenas, LGBTQIA+ e povos ciganos.
} 
conseguinte, interferindo na elaboração das linguagens documentárias.

Como teoria interpretativa, a teoria das representações sociais auxilia em análises de pesquisa, cujo objetivo é verificar como certas representações se materializam via discurso, serve também para explicar fenômenos construídos socialmente, por meio das relações sociais (indivíduo e o coletivo e vice-versa).

A teoria da representação social teve como precursor Émile Durkheim. No entendimento de Émile Durkheim, as representações eram vistas de forma separada como: representação coletiva e representação individual, sem que estas possuíssem interação entre si, tornando-se uma teoria estática (ALVESMAZZOTI, 2000).

A teoria da representação de Durkheim serviu de base para Serge Moscovici $(1978 ; 2003)$ desenvolver a teoria das representações sociais. Serge Moscovici, ao contrário de Durkheim, identificou que o indivíduo faz parte do contexto social. Isso significa que há uma relação de troca entre o indivíduo e o grupo social do qual faz parte, constituindo-se em um conhecimento coletivo que retrata uma determinada realidade. É uma teoria que auxilia na compreensão dos saberes construídos via relação intersubjetiva e que, por meio dessa construção, efetua o surgimento de significados construídos via linguagem.

A teoria das representações sociais oferece também uma análise ampla e detalhada sobre a complexidade relacionada à interação entre sujeitorealidade-intersubjetividade-objetividade e rompe com a dualidade ciênciaverdade e senso-comum-ilusão (GUARESCHI; JOVCHELOVITCH, 1995).

As representações de grupos marginalizados, representada de maneira negativa, surgem nas representações sociais na forma de estigmas ${ }^{6}$, isso porque o indivíduo e/ou grupo social "tomam forma e constroem em relação a uma realidade social" (GUARESCHI; JOVCHELOVITCH, 1995, p. 18), e

6 "Os estigmas são construções sociais, que se originam de atitudes carregadas de préconceitos de pessoas que se consideram pertencentes a um grupo superior sobre o outro, que o considera membro de outro grupo" (TELLA, 2008, p.155). Nesse sentido, pode destacar a partir desse cenário elementos que diferenciam os grupos legitimando e reafirmando estereótipo que proporciona em atos discriminatórios. 
quando essa realidade construída estruturalmente com viés colonialista, patriarcalista, sexista, LGBTIA+ fóbica e eurocêntrica, o indivíduo e/ou grupo social, tende a representar a sociedade nesses vieses.

Nesse sentido, essa configuração, registrada e legitimada como estigma, quando não são desconstruídas, "resistem e perpetuam uma ordem social que deve ser radicalmente questionada" (GUARESCHI; JOVCHELOVITCH, 1995, p. 21). Para os mesmos autores, o questionamento refere-se às condições históricas de produção e reprodução relacionado aos efeitos catastróficos e simbólicos na vida de diversas pessoas.

Muitas produções e reproduções que estabelecem efeitos simbólicos catastróficos que legitimam os estigmas pautam-se nos processos de objetificação e ancoragem, pois nenhuma mente está ilesa de condicionamento impostos por suas representações construídas via linguagem e/ou cultura (MOSCOVICl, 2003).

Nesse sentido, quando se afirma que as linguagens documentárias não são neutras, é porque elas foram construídas por um processo de condicionamento, tais como valores e crenças, baseado em uma cosmovisão, que engessam, objetificam e ancoram termos ao atribuírem ao grupo marginalizado.

Grupos construtores de linguagens documentárias, ou seja, comunidade discursiva e de especialidade, também estão sujeitos ao condicionamento externo influenciado pela ordem mundial hegemônica, pois a linguagem documentária é, antes de mais nada, a constituição da própria linguagem natural que possui valores culturais, aplicáveis na documentação através de um processo semiótico de descrição metalinguística.

Os valores e as crenças tendem a interferir no processo de representação no que concerne ao enquadramento do conceito ao um determinado termo. Para Moscovici (2003), as representações convencionalizam os objetos, pessoas e acontecimentos, dando formas definitivas, na quais são localizadas em determinadas categorias e partilhadas por um grupo de pessoas/sociedades.

Quando pensamos em linguagem documentária para assumir 
determinada forma, enquadrada em uma determinada categoria, muitas vezes não satisfatória a um determinado grupo ou cultura, possibilita uma representação errônea. Esse fato, pode ser explicado no processo de objetificação e ancoragem, no momento da construção da linguagem documentária quando se enquadra o conceito em um termo representativo, procedimento que pode ocasionar a redução de objetos, seres humanos, culturas desconhecidas, em imagens comuns e essencialistas.

A objetificação depende dos aspectos culturais do sujeito e do contexto na qual esse sujeito se insere. Nesse sentido, os objetos são selecionados e representados a partir de conhecimentos anteriores e com base em critérios religiosos, culturais e valores morais. Portanto, objetivação é "transformar algo abstrato em algo quase concreto, transferir o que está na mente em algo que exista no mundo físico" (MOSCOVICl, 2003, p. 62).

A ancoragem é dar nome às coisas, está relacionada à classificação de objetos ou sujeito os quais são "estranhos" e, por conseguinte, ameaçadores aos olhos de quem se considera parâmetro de comparação. É nesse processo que ocorre a rotulagem, estigmas, o surgimento de estereótipos e é também nesse processo que as representações sociais de um determinado objeto ou indivíduo se manifesta fazendo parte da decisão no momento de categorizar incluindo o processo de escolha e elaboração das linguagens documentárias, termos, às vezes, não condizentes com a realidade.

Portanto, as representações são resultantes do processo de classificação em que se decide o que deve ser evidenciado e representado, ou seja, o que deve fazer parte da linguagem documentária e o que não deve fazer parte, utilizando o método de semelhança e diferença que, de certa forma, induz no processo de exclusão, quando estamos lidando com sujeitos socioculturais, inseridos em uma sociedade que adere a parâmetros euroocidental.

Nesse sentido, as representações, de certa forma, configuram-se como uma relação de poder, um aparelho de controle na organização de objetos e indivíduos e nas inter-relações humanas em que quem está no poder designa e atribui nomes àqueles que estão fora dos padrões: homem, branco, cisgênero, 
heteronormativo e cristão. As representações sociais se dão pelo reconhecimento do outro, tendo o outro como algo diferente de um certo "padrão".

No Brasil, as representações de grupos marginalizados têm por base 0 processo de colonização que nomeou povos originários, pessoas afrodescendentes, em povos primitivos a partir da ideia de raça. A ideia de raça advinda das ciências naturais e reforçada no século XIX pelo racismo científico promoveu a sub-representação e a subalternização desses povos.

Em um contexto que extrapola os problemas brasileiros de identificação dos grupos marginalizados em decorrência de nossa história colonial, encontrase a questão do grupo LGBTQIA+ (sigla que compõem pessoas lésbicas, gays, bissexuais, transsexuais, queer, pansexuais e o mais que está relacionado a pessoas além da sigla, mas consideradas fora dos padrões cisheteronormativos), estes fogem da norma heteronormativa que transgridem o padrão heterossexual.

Nesse sentido, as representações sociais que envolvem o grupo LGBTQIA+, ou seja, a diversidade sexual, que compõem os eixos: o sexo biológico, a identidade de gênero e a orientação sexual (UNFPA, 2010), que as tornam sujeitos subalternos suscetíveis às representações negativas, estão relacionadas à sexualidade, que, no século XVIII, surgiu como construto social e histórico para normatizar e controlar a sociedade, uma espécie de biopoder (FOUCAULT, 1999), que favorecia à burguesia.

Dessa forma, podemos observar como exemplo o termo homossexualismo que ficou por muito tempo no sistema de classificação de Dewey ${ }^{7}$ e também pode ser encontrado em outras linguagens documentárias tais como Vocabulário Básico do Senado Federal (PINHO; GUIMARÃES, 2011). O termo é questionado por pesquisadores da área de Organização do Conhecimento, já que evidenciava o sufixo "ismo" associado à ideia de doença. Em relação à mulher, o controle se baseia na reprodução e na

\footnotetext{
7 O termo homossexualismo na CDD foi alterado por homossexualidade em 2014. É válido enfatizar que além do termo homossexualismo, outras categorias relacionadas ao grupo LGBTQIA+ foram dadas como Psicologia anormal, perversão, transtornos, problema social e distúrbios médicos (SULLIVAN, 2015).
} 
manutenção da família, quando esta não se enquadrava nos padrões estabelecidos, ou não era subordinada ao homem, era tida como mulher delinquente (LOMBROSO; FERRERO, 2017). Nesse termo enquadram-se as prostitutas, histéricas, suicidas, lunáticas, epiléticas e moralmente insanas (SILVA, 2014).

Quando se trata da mulher negra, o eixo de subordinação evidencia-se de forma abrupta, quando considera a mulher negra em "representações conforme à tonalidade de sua cor, suas feições e o formato de seu corpo tais como 'mulata exportação', com uma perspectiva exótica e erotizada" (ROMEIRO, et al, 2019, s/p), ou seja, é concebida como objeto sexual.

Quando a mulher negra não se enquadra na categoria "mulata exportação"8 nem possui o padrão de estética euro-americano, ela é representada como insulto à sociedade brasileira e ao mesmo tempo invisibilizada ou representada em lugar de subalternidade, destinada a servir alguém.

O homem negro, assim como a mulher negra, é subjugado e representado pela cor da pele e seus traços. Segundo Paula, Carvalho e Kodato $(2018, s / p$.$) "a estética negra é apresentada como defeituosa,$ exagerada ou fora do padrão caucasiano", estes são atributos representacionais sobre o corpo negro que gera a desumanização formando a noção de superioridade e inferioridade.

Ao homem negro é associado a um pefil de "assaltantes, estupradores, traficantes ou presidiários" (PAULA; CARVALHO; KODATO, 2018, s/p.); requisito que proporciona o encarceramento em massa ${ }^{9}$. Os estigmas associados à cor da pele também são vistos em dicionários, segundo Neusa Sousa Santos (1983), o dicionário Aurélio (um dos mais conceituados dicionários) associa o verbete negro a sujo, sujeira, dentre outras palavras pejorativas.

\footnotetext{
8 Se configura como um dos mitos raciais, uma representação negativa expressa via estereótipo sobre a sexualização do corpo da mulher negra, integrando o imaginário brasileiro. (SANTANA, 2011).

${ }^{9}$ Ver BORGES, Juliana. O que é encarceramento em massa?. Belo Horizonte/MG: Letramento: Justificando, 2018.
} 
As representações negativas de grupos marginalizados foram pautadas nos discursos produzidos por europeus para justificar a escravidão, por meio da ocupação e conquistas de territórios, de pessoas negras e indígenas e, mais tarde, dos condenados da terra (FANON, 2006).

Em relação aos povos indígenas, estes/as eram considerados bárbaros, selvagens e sem alma e, consequentemente, vistos como não humanos, assim como as pessoas negras, pelos relatos de viajantes nas américas, o que possibilitou na colonização por serem vistos como seres degenerados, que poderiam ser aprisionados e escravizados e, consequentemente, era preciso passar por um processo de evangelização (CASTRO, 2012).

Mais tarde, no século XIX, os indígenas como sujeitos participantes da nação brasileira foram romantizados em obras literárias, destacando a mitopeia, Iracema, e a narrativa épica, O Guarani, ambos de José de Alencar, como também no poemeto I-Juca Pirama, de Gonçalves Dias, colocando-os como heróis nacionais (CASTRO, 2012), e suas feições e corpos traçados e narrados por uma representação embranquecida mais próxima da estética europeia, fundamentados nos valores medievais da cavalaria, distanciando-os dos valores indígenas, o que possibilitou uma representação estruturada na modificação do imaginário social.

É válido lembrar que, atualmente, ainda se percebe que há no imaginário da sociedade a representação do/as os/as indígenas, considerandoos primitivos ${ }^{10}$ por morarem em aldeias. No entanto, a escolarização indígena possibilitou o surgimento de autores/as de sua própria história. Segundo Franca e Silveira (2014, p. 71),

a literatura escrita indígena vai além da publicação de livros com a temática indígena. Ela contém a possibilidade de autorrepresentação de povos que por vezes foram mantidos em categoria secundária no panorama político e cultural

10 Pode-se evidenciar esse tipo de representação presente na fala do presidente Jair Bolsonaro, um político nacionalista de extrema direita. Jair Bolsonaro relata em UOL Notícias, no dia 23 de janeiro de 2020 que "com toda a certeza, o índio mudou, tá evoluindo. Cada vez mais o índio é um ser humano igual a nós". Outra fala infeliz e racista data em 22 de abril de 2015, em Campo Grande News, "Os índios não falam nossa língua, não têm dinheiro, não têm cultura. São povos nativos. Como eles conseguem ter $13 \%$ do território nacional?"; dentre outras falas racistas que o presidente relatou ao longo do seu mandato e anterior a este. 
nacional.

A representação social de povos ciganos se configura no modo de ser e viver livremente, ou seja, serem nômades ${ }^{11}$, além do estigma da pele. A criação do imaginário social referente aos povos ciganos deu-se por meio das interações com os europeus no século XV (CARVALHO et al, 2012).

Sendo representado como um grupo racializado também possibilitou em ter uma representação negativa que o desumaniza. A desumanização, por serem nômades, associa os povos ciganos a mendigos, delinquentes, trambiqueiros, vagabundos (CARVALHO et al, 2012), imoral, ignorante, herege e facínora (FAZITO, 2006). Em relação às suas práticas culturais, são vistos como arruaceiros.

As representações sociais de grupo marginalizados possuem dois lados: uma retrata de maneira negativa que possibilita a desumanização e, outro lado, que possibilita a exotificação visualizada pelas vestimentas, traços físicos, misticismo e práticas oraculares.

Contudo, o processo de representação, um sistema simbólico, surgiu com a perspectiva de dominação através dos tempos, conflitos e opressões que possibilitou representar indivíduos via dicotomização e hierarquias baseadas em gênero, raça, sexualidade, classe social e territórios geográficos; assim foram sub-representados ou receberam representação negativa que produz desigualdades sociais evidenciadas até hoje na sociedade. Essas desigualdades representacionais estão presentes nas linguagens documentárias utilizadas em bibliotecas, tais como a CDD e a CDU que objetivam representar documentos para fins de recuperação.

\section{A LINGUAGEM DOCUMENTÁRIA: DA SUB-REPRESENTAÇÃO À SUPERAÇÃO DAS DESIGUALDADES NA REPRESENTAÇÃO}

A representação do conhecimento se estabelece graças à eficácia da linguagem em modelar o pensamento humano, assim a linguagem natural

11 "[...] efeitos dos constantes deslocamentos forçados, produto de grande violência física e simbólica" (FAZITO, 2006, p. 692) 
disponibiliza mecanismos linguísticos capazes de funcionarem como descritores, explorando elementos de significação, a qual é marcada por questões semânticas, já que evidencia sentidos produzidos em documentos, assim como é marcada por discursos, que enfatizam os interesses de grupos e na forma como representam a realidade, além de a linguagem se constituir, no processo de representação da realidade, como signo.

Além de uma análise semiótica sobre esse fenômeno linguístico, utilizado pela Organização do Conhecimento, é possível compreender sua atuação como um elemento linguístico isotópico (BARTHES, 1971; GREIMAS, 1973), devido à sua natureza em direcionar o entendimento do usuário para elementos que estão além do documento secundário - recursos direcionadores da recuperação da informação, fator que também marca a rede semântica em que o documento é constituído. Sob tal função de referenciação, este signo também atua como índice, no entanto não recupera todos os discursos inerentes à concepção do documento, mas somente ao estigma institucionalizado através da linguagem documentária.

Ainda, em aspectos discursivos, observando as características inerentes à enunciação, é importante destacar que este descritor atua como uma dêixis (MAINGUENEAU, 1996), visto que possui propriedade de economia comunicativa, pois recupera todo um enunciado, no caso, as propriedades do documento primário, assim como as premissas do domínio relacionado e as atribuições enunciativas da comunidade discursiva.

Nessa perspectiva, deveria recuperar todos os elementos enunciativos, discursos e pragmáticos acerca dos conceitos, porém, na maioria das vezes, apenas recupera a construção pejorativa, pois é essa que está marcada no imaginário popular. Além disso, há pouca produção documental que evidencie um papel honrado, legitimado e inclusivo a esses grupos sociais.

Toda essa situação que envolve a constituição de linguagem documentária evidencia a sistematização ética e analítica por parte das áreas responsáveis, assim como seus profissionais, cuja função é extremamente valiosa e cuidadosa. No entanto, não se pode perder de vista que esses procedimentos envolvem o encontro com ideologias, discursos de poder, atos 
enunciativos, inferências, implicaturas, que interferem na legitimidade, institucionalidade e representatividade do documento e do conhecimento veiculado por ele.

Sendo assim, marcas históricas evidenciam a preterição por termos que evidenciem o discurso e o conhecimento de grupos marcados por uma inferioridade discursiva, pois são marcados historicamente por não terem seus documentos legitimados, nem são vistos socialmente como produtores de conhecimento, os quais, no atual período histórico, devem e merecem ser reconhecidos, por conseguinte há a necessidade da revitalização lexical a fim de identificar esses grupos tanto na inclusão de referências positivas, como na exclusão de termos que evoquem conceitos com traços semânticos de inferioridade, pejorativos e estereotipados.

Lara (2004, p. 233) ainda aponta qualidades fundamentais para a elaboração de uma linguagem documentária eficiente, de proposição organizacional e competente no desempenho de seu "papel de instrumento de comunicação". Essas qualidades requerem metodologia adequada para a construção da linguagem documentária, em busca da univocidade e assim a normalização semântica. Para tanto, é preciso "funcionar como código inteligível e fonte para interpretação do sentido" (LARA, 2004, p. 233).

É preciso entender que essa qualidade fundamental para modelar um termo necessita, na prática da representação, aceitar que há uma dualidade simbólica, portanto há um dialogismo ideológico e isso se perfaz a priori por seus registros, nessa perspectiva, conforme aponta Lara (2007, s/p.), é válido destacar que "a principal contribuição da Terminologia não é a identificação dos termos em si, mas a validação social das escolhas de forma e conteúdo, como expressão pragmática da observação dos discursos das comunidades de uso".

Diante desse pressuposto sobre a atuação da Terminologia clássica, é válido destacar o argumento de Maciel (2010, p. 397):

Não se pode esquecer que, após a II Guerra Mundial, a linguagem especializada era privilégio de uma elite que dava primazia ao aspecto cognitivo da ciência e à padronização de sua comunicação com vistas à univocidade de sentido. No entanto, pouco a pouco, o desenvolvimento sociopolítico, cultural e tecnológico divulgou a informação científica a ponto 
de torná-la direito de todos, exigindo, assim, que a linguagem do especialista saísse de seu hermetismo e fosse compreendida pelo leigo.

Frente a isso, é compreensível a ideia de que a influência na representação do conhecimento é modelada também por um conjunto de termos tradicionalmente escolhidos à base de uma ideologia dominante de uma época de ascensão da necessidade de padronizar os termos aplicados na confecção de documentos secundários.

Por outro lado, é válido destacar os trabalhos terminológicos fundamentados em propostas sociolinguístico-terminológico, encabeçadas por Cabré (2010) e Temmerman (2001) que, ao apresentarem uma proposta de terminologia sociocognitiva, questionam a realidade mentalista do conceito, a rigidez dos sistemas de árvore de domínio, a negação da variação, o desconhecimento da multiplicidade dos falares profissionais e a ausência do funcionamento linguístico dos termos no plano sintático e no plano semântico (ISQUERDO; FINATTO, 2010, p. 403).

Diante disso, entende-se que a Teoria Comunicativa da Terminologia, proposta por Cabré (1999), tem muito a contribuir, assim como a linguística na elaboração e aplicação da linguagem documentária para garantir a representatividade dos grupos marginalizados, inferiorizados e excluídos, já que propõe "ver os termos como unidades linguísticas, enfatizando a função da língua como instrumento de comunicação" (LARA, 2010, p. 4).

Sendo assim, a linguagem documentária, por conseguinte a Terminologia possuem a função de garantir a padronização na comunicação especializada, através de uma linguagem preparada para garantir a representação e a recuperação da informação, no entanto é preciso atentar como linguagem documentária apresenta termos que legitimem a existência de aspectos sociais, culturais, ideológicos, políticos de outros grupos, outros domínios, outras comunidades discursivas, aspectos presentes também na sociolinguística, que não são integrantes pertencentes ao discurso dominante. 


\section{CONSIDERAÇÕES FINAIS}

A presente reflexão teve como objetivo analisar o impacto da linguagem no processo de representação, os procedimentos linguísticos que envolvem o processo de representação, com base em teorias da linguagem e na teoria da representação social aplicados na linguagem documentária a fim de compreender a pré-disposição do sistema de organização do conhecimento e o impacto desse processo na representatividade de grupos marginalizados, a saber: negros/as, indígenas, ciganos/as, mulheres e pessoas do grupo LGBTIA+.

Como bem tratado no decorrer do texto, a linguagem documentária deve seguir princípios éticos e diretrizes institucionais, propostas por um regime de informação que legitima somente uma ordem discursiva. A linguagem documentária tem por base a terminologia que é constituída por normas que modelam o conceito, por um determinado contexto, tornando um léxico unívoco que representa um determinado discurso. No entanto, nem sempre a ordem discursiva equivale ao que se representa de fato ou reporta-se a uma realidade quando se trata de representar grupo marginalizados.

Além disso, ficou evidenciado nas discussões que o processo de fundamentação semântica é enraizado em marcas discursivas que agregam traços de significação marcadas historicamente, ou seja, a composição discursiva corrobora a indicação de semas e classemas que constituem 0 semema no processo de representação frente a domínios e comunidades discursivas, o que incorpora no termo todas essas marcas semânticas como isotópicos.

Como bem enfatizado, é preciso questionar se no processo colonial e neocolonial, itens significativos relacionados ao grupo marginalizados foram tratados como enunciados que os desqualificam e que tornam suscetíveis a uma representação negativa.

As representações negativas, isto é, representações contrárias a como os grupos se identificam, originadas historicamente, constituem-se em uma ordem discursiva com base em uma ideologia que inferioriza certos grupos. 
A ideologia também se materializa nos discursos do senso comum e em discursos científicos e ambos fazem parte do sistema simbólico de representação que configura a sociedade, por conseguinte emplacando 0 imaginário popular e a representação desses símbolos, como réplicas constantes nos discursos cotidianos. Sendo a linguagem carregada de significação e esta um elemento dinâmico da sociedade, esta faz parte da representação social relacionado ao grupo historicamente marginalizado.

A representação social tem grande influência na construção da linguagem documentária e nela estão incutidos os aspectos mencionados acima quando está engendrada com parâmetros hegemônicos de um determinado grupo, o que pode acarretar sub-representação de sujeitos, grupo sociais e culturais que não fazem parte do sistema simbólico de representação dominante.

Diante do exposto, pode-se concluir que:

- a linguagem deve ser analisada tanto pela convencionalidade do signo quanto pela relação com o extralinguístico (experiência colateral). Desse modo, uma relação direta com as práticas sociais será mais efetiva para a representação adequada dos signos;

- a linguagem documentária pautada na terminologia reporta-se aos conceitos construídos pelo discurso dominante. Sendo assim, a representação no contexto da organização do conhecimento reproduz os vieses caso não seja estipulado um tipo de vigilância terminológica que neutralize o maior número de sub-representações e representações negativas;

- a representação social através do conceito de ancoragem reestabelece uma relação direta com as hierarquias construídas pelo discurso dominante. Esse conceito é determinante para entender o processo de estigmatização e produção de distinções no interior da cultura e pode favorecer a reconstrução de mecanismos que aplacam representações sociais que inviabilizam a imagem das comunidades discursivas;

- os grupos marginalizados são representados inadequadamente por grupos estabelecidos que produziram discursos pseudocientíficos, segmentaram os sujeitos e deixaram grupos, culturas e expressões culturais 
em condição subalterna;

- a linguagem documentária recorre às categorias sociais pseudocientíficas e classifica os documentos e de certo modo, os próprios grupos historicamente marginalizados. Categorias realmente científicas são aquelas que se pautam em uma representação cada vez mais próxima da realidade dos grupos representados;

- a autorepresentação é um direito e um pressuposto ético que deve fazer valer a opinião dos grupos historicamente marginalizados no momento de construir a sua própria imagem e identificação social. A autorepresentação deve, ao fim e ao cabo, favorecer a estruturação de linguagens documentárias mais afinadas ao desenvolvimento da sociedade contemporânea.

Sendo assim, é preciso haver estudos contínuos acerca do papel da linguagem documentária, pois esta é fundamental para o processo de representação do conhecimento e elaboração de documentos secundários. Contudo, não pode ser um instrumento estagnado, a sua atualização deve ser constante e manter ativo o questionamento da abordagem e da dimensão referente à preocupação com a inclusão e representatividade.

A linguagem documentária tem papel determinante na materialização dos avanços conquistados por esses grupos sociais e, nesse sentido, também atua socialmente para que a ciência seja cada vez mais democrática.

\section{REFERÊNCIAS}

ALVES-MAZZOTTI, A. J. Representações sociais: desenvolvimentos atuais e aplicações à educação. In: CANDAU, V. M. (Org). Linguagem: espaços e tempo no ensinar e aprender. In: ENCONTRO NACIONAL DE DIDÁTICA E PRATICA DE ENSINO (ENDIPE), 10., Rio de Janeiro. Anais [...] Rio de Janeiro: LP\&A, 2000.

BAKTHIN, M. M.; VOLOCHINOV, V.N. Marxismo e filosofia da linguagem: problemas fundamentais do método sociológico da linguagem. São Paulo: Hicitec, 2006

BARTHES, R. Elementos da Semiologia. São Paulo: Cultrix, 1971

BENVENISTE, E. Problemas de linguística geral. Trad. Maria da Glória Novak; Luiza Neri. São Paulo: Ed. Nacional, 1988. 
BORGES, J. O que é encarceramento em massa?. Belo Horizonte/MG: Letramento: Justificando, 2018.

CANDIDO, M. R.; FERES JÚNIOR, J. Representação e estereótipos de mulheres negras no cinema brasileiro. Rev. Estud. Fem. vol.27 no.2 Florianópolis 2019. Disponível em: https://www.scielo.br/scielo.php?script=sci_arttext\&pid=S0104026X2019000200207. Acesso em: 20 jun.2020.

CARLAN, E. Sistemas de organização do conhecimento: uma reflexão no contexto da Ciência da Informação. 2010, 195f. Dissertação (Mestrado em Ciência da Informação) - Universidade de Brasília, Brasília, 2010. Disponível em: https://repositorio.unb.br/bitstream/10482/7465/1/2010_ElianaCarlan.pdf. Acesso em: 04 de jun.2020.

CARVALHO, N. C; LIMA, M. E. O.; FARO, A.; SILVA, C. A. F. Representações sociais dos ciganos em Sergipe: contato e estereótipos. Psicologia e saber social, v.1, n. 2, p. 232-244, 2012. Disponível em: https://www.epublicacoes.uerj.br/index.php/psi-sabersocial/article/view/4902/3625. Acesso em: 20 jun. 2020.

CASTEL, R. As metamorfoses da questão social: uma crônica do salário. Editora Vozes: Petropólis, Rio de Janeiro, 2008.

CASTRO, R. N.de. A representações indígenas no processo de colonização do Brasil. Revista eletrônica história em reflexão. v.6, n.11 - UFGD- Dourados, jan/jun, 2012. Disponível em:

https://ojs.ufgd.edu.br/index.php/historiaemreflexao/article/view/1875. Acesso em: 15 de jun.2020

FAZITO, D. A identidade cigana e o efeito de "nomeação": deslocamento das representações numa teia de discursos mitológico-científicos e práticas sociais. Rev. Antropol., v. 49, n. 2, São Paulo, Jul/dez, 2006. Disponível em: https://www.scielo.br/scielo.php?script=sci_arttext\&pid=S003477012006000200007. Acesso em: 15 jun.2020.

FOUCAULT, M. Em defesa da sociedade. São Paulo: Editora Martins Fontes, 1999.

GARCÍA MARCO, F.J. Avances en organización del conocimiento en España: los II encuentros sobre organización del conocimiento en los sistemas de información y documentación. In: GARCÍA MARCO, F.J. (ed.) Organización del conocimiento en sistemas de información y documentación. Zaragoza: Libreria General, p.7-12. 1997. Disponível em: https://dialnet.unirioja.es/servlet/articulo?codigo $=595067$. Acesso em: 10 jun. 2020.

GREIMAS, A. J.; COURTÉS, J. Dicionário de Semiótica. 2. ed. São Paulo: Contexto, 2016. 
GREIMAS, A.J. Semântica Estrutural. Trad. Haquira Osakape e Izidoro Blikstein. São Paulo: Cultrix, 1973.

GUARESCHI, P.; JOVCHELOVITCH, S. (Org.). Texto sem representações sociais. 2. ed. Petrópolis:Vozes, 1995.

GUTIÉRREZ, A. G. Teoria da la inidización: nuevas parámetros de investigación. Transinformação, v. 1, n. 2, 1989. Disponível em: http://hdl.handle.net/20.500.11959/brapci/22889. Acesso em: 13 jun. 2019.

HJELMSLEV. L. Ensaios Linguístico. Trad. Antônio de Pádua Danesi. São Paulo: Perspectiva, 1991.

HJORLAND, B. Concept Theory. Journal of the American Society for Information Science and Techonology, v. 60, n. 8, p. 1519-1536, 2009

HJORLAND, B. Domain analysisin informationscience: Elevenapproachestraditionalas wellas innovative. Journal of Documentation, v. 58 , n. 4, p. 422462, ago. 2002.

HODGE, G. Systems of Knowledge Organization for Digital Libraries: Beyond Traditional Authority Files. The Digital Library Federation, 2000.

ISQUERDO, A. N; FINATTO, M. J. B. (org.). As ciências do léxico:

lexicologia, lexicografia, terminologia. v.4. Porto Alegre: Editora da UFRGS, 2010.

LARA, M. L. G. Linguagens documentárias: instrumentos de mediação e comunicação. Revista Brasileira de Biblioteconomia e Documentação, v. 26, n. 1-2, p. 72-80, 1993. Disponível em:

https://brapci.inf.br/_repositorio/2011/10/pdf_e15bf0575c_0019242.pdf. Acesso em: 10 de jun.2020.

LARA, M. L. L. G. Linguagem documentária e terminologia. Transinformação, Campinas, v. 16, n. 3, p. 231-240, 2004. Disponível em:

https://www.scielo.br/scielo.php?pid=S0103-

$37862004000300003 \&$ script=sci_abstract. Acesso em: 10 de jun.2020.

LARA, M. L. L. G. O unicórnio (o rinoceronte, o ornitorrinco...), a análise documentária e a linguagem documentária. DataGramaZero, v. 2, n. 6, 2001. Disponível em:

https://brapci.inf.br/_repositorio/2010/01/pdf_ae2d5ed349_0007456.pdf. Acesso em 10 de jun.2020.

LARA, M. L. L. G.; TÁLAMO, M. F. G. M. Uma experiência na interface linguística documentária e terminologia. DataGramaZero, v. 8, n. 5, 2007. Disponível em: https://brapci.inf.br/index.php/res/v/6681. Acesso em: $10 \mathrm{de}$ jun.2020. 
LOMBROSO, C.; FERRERO, G. A mulher delinquente: a prostituta e a mulher normal. Curitiba: antoniofontoura, 2017.

MAIMONE, G. D.; TÁLAMO, M. F. G. M. Linguística e terminologia: contribuições para a elaboração de tesauros em ciência da informação. DataGramaZero, v. 12, n. 2, 2011. Disponível em: https://brapci.inf.br/index.php/res/v/7356. Acesso em: 10 de jun.2020.

MAINGUENEAU, D. Elementos da linguística para o texto literário. Trad. Maria Augusta Bastos de Mattos. São Paulo: Martins Fontes, 1996.

MOSCOVICl, S. Representações sociais: investigações em Psicologia Social. Petropólis: Vozes, 2003.

SURVIVAL, O que Jair Bolsonaro, presidente-eleito disse sobre os povos indígenas do Brasil. Disponivel em: https://survivalbrasil.org/artigos/3543Bolsonaro. Acesso em: 18 nov.2020.

PÊCHEUX, M. Semântica e discurso: uma crítica à afirmação do óbvio. Trad. Eni Pulcinelli Orlandi et al. Campinas: Editora da Unicamp, 1997.

PEIRCE, C. S. Semiótica. Trad. José Teixeira Coelho Neto. 4aㅗ ed. São Paulo: Perspectiva, 2017.

PINHO, F. A.; GUIMARÃES, J.A.C. A precisão nas linguagens de indexação: um estudo com a temática da homossexualidade masculina. XII Encontro Nacional de Pesquisa em Ciência da Informação (ENANCIB). Brasilia, Distrito Federal, Anais... Distrito Federal:UnB, 2011.

REALE, G; ANTISERI, D. História da filosofia, 2: Patrística e Escolástica. Trad. Ivo Stormiolo. São Paulo: Paulus, 2005.

REALE, G; ANTISERI, D. História da filosofia, 4: de Spinoza a Kant. Trad. Ivo Stormiolo. São Paulo: Paulus, 2005.

SANTANA, P. M. dos S. A poesia combatendo esteriótipos: uma análise de 'mulata exportação' de Elisa Lucinda.e-escrita Revista do curso de letras da UNIABEU, Nilópolis, v.2, n. 5, Mai.-Ago, 2011. Disponivel em: https://revista.uniabeu.edu.br/index.php/RE/article/view/163/pdf_40.Acesso em: 13 jun.2020.

SAUSSURE, F. Curso de linguística geral. Trad. Bras. Antônio Chelini et al. São Paulo: Cultrix, 2006.

SILVA, E. E. D. da. A (des) construção da identidade social de mulher criminosa: estigmas, negociações e diferenças. In: Direitos, Gênero e Movimentos sociais I: Congresso Nacional do CONPEDI, 1., 2014, João Pessoa. Anais... Florianópolis: CONPEDI, 2014. p. 72 - 101. 
SILVA, L. R. da. Não me chame de mulata: uma reflexão sobre a tradução em literatura afrodescendente no Brasil no par de línguas espanholportuguês. Trab. Ling. Aplic., Campinas, v. 57, n.1, p. 71-88, jan./abr. 2018. Disponivel em: https://www.scielo.br/pdf/tla/v57n1/0103-1813-tla-57-010071.pdf. Acesso em: 12 jun.2020.

SILVA, N. S. Tornar-se negro: as vicissitudes da identidade do negro brasileiro em ascensão social. Rio de Janeiro: Edições Graal, 1983.

SILVEIRA, L. F. B. Curso de Semiótica geral. São Paulo: Quartier Latin, 2007. SULLIVAN, D. Uma breve história da homofobia na Classificação Decimal de Dewey. Medium.com. 29 Jul 2015.

TÁLAMO, M. F. G. M.; LARA, M. L. L. G. Interface entre linguística, terminologia e documentação. Brazilian Journal of Information Science, v. 3, n. 2, 2009. Disponível em: https://revistas.marilia.unesp.br/index.php/bjis/article/view/361. Acesso em: 15 de jun.2020.

UNFPA. Fundo das Nações Unidas. Adolescente e Jovens para a Educação entre Pares: Saúde e Prevenção nas escolas. Brasília, n. 69, 2010. Disponível em:http://www.unfpa.org.br/Arquivos/guia_diversidades.pdf . Acesso em: 23 nov. 2019.

\title{
LANGUAGE AND DOCUMENTARY LANGUAGE IN THE KNOWLEDGE REPRESENTATION PROCESS OF MARGINALIZED GROUPS: THEORETICAL REFLECTIONS
}

\begin{abstract}
Introduction: The representation of knowledge is responsible for the interoperability between systems, users, domains, while that it returns to society a legitimate information network capable of offering viability to the articulated information through the retrieval of information. Objective: Thus, this work aims to analyze the impact of language in the representation process with respect to semantic, semiotic and discursive issues in order to understand the pre-disposition of the knowledge organization system, which is guided by terminological choices, for legitimize representation, more specifically, discuss about the institutionality of concepts and the way in which the representation of marginalized groups understood in this work as blacks, indigenous people, gypsies, women and people of the LGBTIA+ group. Methodology: For this, a qualitative methodology, descriptive type, exploratory, theoretical-bibliographic and critical approach was applied. Conclusions: Therefore, it is understood that social representation has a great influence on the construction of documentary language and hegemonic parameters of a certain group are engendered, which can lead to under-representation of subjects, social and cultural groups that are not part of the symbolic system dominant representation.
\end{abstract}


Descriptors: Knowledge Representation. Marginalized groups. Documentary Language.

\title{
LENGUAJE Y LENGUAJE DOCUMENTAL EN EL PROCESO DE REPRESENTACIÓN DEL CONOCIMIENTO GRUPO DE CONOCIMIENTOS: REFLEXIONES TEÓRICAS
}

\begin{abstract}
RESUMEN
Introducción: La representación del conocimiento es responsable de la interoperabilidad entre sistemas, usuarios, dominios, al mismo tiempo que devuelve a la sociedad una red de información legítima capaz de, a través de la recuperación de información, ofrecer viabilidad a la información articulada. Objetivo: Así, este trabajo tiene como objetivo analizar el impacto del lenguaje en el proceso de representación con respecto a cuestiones semánticas, semióticas y discursivas con el fin de comprender la predisposición del sistema de organización del conocimiento, que se guía por elecciones terminológicas, para legitimar la representación, más específicamente, discutir sobre la institucionalidad de conceptos y la forma en que se lleva a cabo la representación de los grupos marginados entendidos en este trabajo como negros, indígenas, gitanos, mujeres y personas del grupo LGBTIA+. Metodología: Para ello se aplicó una metodología cualitativa, de tipo descriptiva, exploratoria, teórico-bibliográfica y crítica. Conclusiones: Por tanto, se entiende que la representación social tiene una gran influencia en la construcción del lenguaje documental y se engendran parámetros hegemónicos de un determinado grupo, lo que puede llevar a una subrepresentación de sujetos, grupos sociales y culturales que no forman parte del sistema simbólico representación dominante.
\end{abstract}

Descriptores: Representación del conocimiento. Grupos marginados. Lenguaje documental.

Recebido em: 02.07.2020

Aceito em: 05.02.2021 